\title{
A Study on Physical Properties of Mortar Mixed with Fly-ash as Functions of Mill Types and Milling Times
}

\author{
Sung Kwan Seo***, Yong Sik Chu ${ }^{*,}$, Kwang Bo Shim**, and Jae Hyun Jeong* \\ *Energy \& Environmental Division, Korea Institute of Ceramic Engineering and Technology, Jinju 52851, Korea ${ }^{1)}$ \\ **Division of Materials Science and Engineering, Hanyang University, Seoul 04763, Korea ${ }^{2)}$ \\ (Received January 27, 2016; Revised May 9, July 4, 2016; Accepted July 7, 2016)
}

\begin{abstract}
Coal ash, a material generated from coal-fired power plants, can be classified as fly ash and bottom ash. The amount of domestic fly ash generation is almost 6.84 million tons per year, while the amount of bottom ash generation is 1.51 million tons. The fly ash is commonly used as a concrete admixture and a subsidiary raw material in cement fabrication process. And some amount of bottom ash is used as a material for embankment and block. However, the recyclable amount of the ash is limited since it could cause deterioration of physical properties. In Korea, the ashes are simply mixed and used as a replacement material for cement. In this study, an attempt was made to mechanically activate the ash by grinding process in order to increase recycling rates of the fly ash. Activated fly ash was prepared by controlling the mill types and the milling times and characteristics of the mortar containing the activated fly ash was analyzed. When the ash was ground by using a vibratory mill, physical properties of the mortar mixed with such fly ash were higher than the mortar mixed with fly ash ground by a planetary mill.
\end{abstract}

Key words : Fly ash, Vibratory mill, Planetary mill, EMM, Activated material, Concrete

\section{Introduction}

S ince the industrialization in the $19^{\text {th }}$ century, energy usage has been sharply increased, and the usage of fossil fuels also tends to be increased. In addition, as environment pollution problems due to combustion gas and coal ash, etc. during combustion process of fossil fuels are also emerging, studies on recycling methods of the coal ash are being consistently conducted. ${ }^{1)}$

Domestic generation of coal ash is on the level of $8.35 \mathrm{mil}-$ lion tons/year, about $80 \%$ of which is reported to be fly ash (6.84 million tons) and $20 \%$ bottom ash (1.51 million tons). ${ }^{2)}$ In general, the fly ash is used as a concrete admixture, a subsidiary raw material for cement, etc., while the bottom ash is used as a bank material, etc. However, not only most of bottom ash but also some flay ash is used for landfill. ${ }^{3-4)}$ Accordingly, the landfill amount of coal ash is being gradually increased, which is also attributed to an increase in generation of coal ash exceeding specification (unburned carbon of more than 5\%) due to the use of low-grade coal. ${ }^{5}$

In domestic mortar and concrete plants, purified and residue fly ash are used mixed, where the residue fly ash is used mostly after undergoing milling process. At this time, fineness of the residue fly ash is controlled to 3,000 $3,500 \mathrm{~cm}^{2} / \mathrm{g}$, which is to meet the fineness criterion (higher

${ }^{\dagger}$ Corresponding author : Yong Sik Chu

E-mail : yschu@kicet.re.kr

Tel : +82-55-792-2463 Fax : +82-55-792-2469 than $3,000 \mathrm{~cm}^{2} / \mathrm{g}$ ) for KS L 5405 fly ash (based on type 2). On the other hand, the purified fly ash is used in unground state as the fineness criterion is exceeded. However, in some advanced countries such as US, etc. the purified ash is also used after milling, in the process of which a vibratory mill, etc. may be employed. ${ }^{6)}$ For milling of the fly ash, fullpledged studies have been conducted since 1990's, with its study and utilization having occurred primarily in US, Europe and Canada, etc. In the latter half of 1990's, V. M. Malhotra and O. Kayali et al. have studied strength enhancement effects as a function of fineness of fly ash. These authors published that strength values were rather reduced beyond a certain fineness although strength characteristics were improved as the fineness of fly ash was increased. ${ }^{7-8)}$ In the early half of 2000's, Vladimir Ronin et al. conducted studies on activation of fly ash, and claimed that activation was attributable to particle defects (crack, dislocation, etc.) produced during milling process. ${ }^{9-10)}$ Although the usage of active fly ash developed by them, i.e. substitution of cement with active fly ash was on the level of $30 \sim 50 \%$, domestic usage of fly ash is still on the level of only $10 \sim 15 \%$.

In the present study, active fly ash for an increase in substitution for cement was manufactured by using purified fly ash produced in the domestic $\mathrm{N}$ powerplant as a byproduct. To prepare active purified fly ash, each powder characteristics were analyzed and evaluated by diversified control of mill types and milling times, etc. In addition, workability and compressive strength characteristics of the mortar mixed with fly ash as a function of milling conditions were 
analyzed in an attempt to derive optimum activity conditions.

\section{Experimental Procedure}

To analyze and evaluate physicochemical characteristics of fly ash as functions of mill types and milling times, fly ash produced at the thermal power plant of domestic $\mathrm{N}$ Company was received for use. Also, as a mill to manufacture active fly ash, a vibratory mill (WTVM, Woongbi Machinery, Korea) and a planetary mill (Pulverisette 5, Fritsch, Germany) were employed as shown in Fig. 1. Chemical composition of fly ash was analyzed by the wet method, particle size distribution measured by a particle size analyzer (LA-950V2, Horiba, Japan), crystalline phases analyzed by X-ray diffraction analyzer (D5005D, Ziemens, Germany), and microstructure observation conducted by using a scanning electron microscope (SM300, Topcon, Japan). In addition, a transmission electron microscope (JEM-2000EX, Jeol, Japan) was employed for microstructure observation of active powders.

Also, to evaluate strength characteristics of fly ash as a function of mill type and time, manufacturing experiments for cement mortar were conducted according to "Strength test method for cement (KS L ISO 679)". For cement, OPC (Type 1 Ordinary Portland Cement) of domestic H Company was used, along with $\mathrm{KS}$ standard sand sold domestically being used as the standard sand. Here, the usage of fly ash substituted for $10 \%$ of cement ( $45 \mathrm{~g}$ of fly ash $+405 \mathrm{~g}$ of OPC), and thus-prepared specimens were cured in water of constant-temperature water tank at $21^{\circ} \mathrm{C}$ for 3 days, 7 days and 28 days for measurement of compressive strengths per material age. Also, to analyze and evaluate workability of mortar mixed with fly ash, flow experiment was also conducted in accordance with "Compressive strength test method for hydraulic cement mortar(KS L 5105)". In addi-

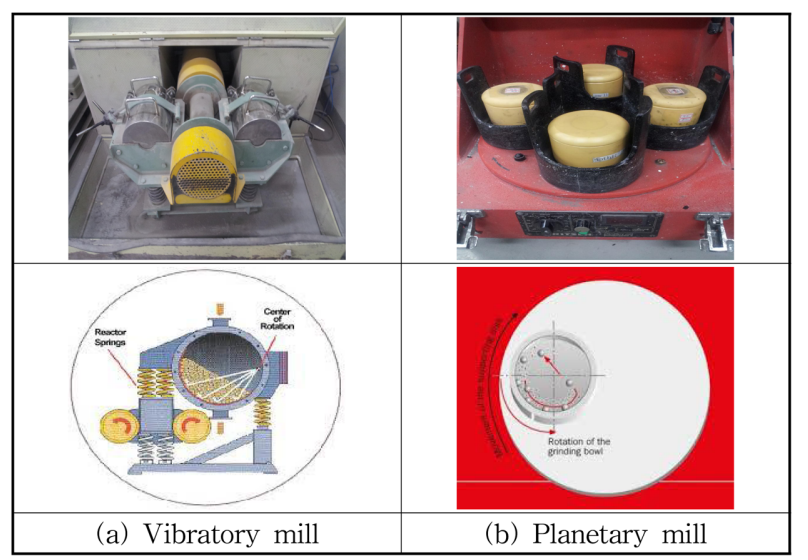

Fig. 1. Various mill types. tion, crystalline phases and microstructures were observed for hydrates of cement mixed with fly ash.

\section{Results and Discussion}

\subsection{Milling characteristics of fly ash}

\subsubsection{Characteristics of unground fly ash}

Fly ash produced as a byproduct in the thermal power plant of domestic N Company was received for chemical analysis, with the analysis results shown in Table 1.

As indicated in Table $1, \mathrm{SiO}_{2}$ content in fly ash was $49.9 \%$ $\mathrm{Al}_{2} \mathrm{O}_{3}$ content $19.2 \%$, unburned carbon content $2.64 \%$, with small amounts of alkali components being also present. In general, to use the fly ash as an admixture for cement and concrete, the ignition loss for fly ash should be controlled to be less than $5 \%$, and the ignition loss is expressed to be usable as a scale for the amount of unburned carbon according to "Guideline for quality management of remicon and ascon (Announcement from Ministry of Land, Infrastructure \& Transport No. 2014-300)". Therefore, the amount of unburned carbon (2.64\%) in Table 1 could be inferred to show the fly ash having satisfactory quality. To check for crystalline states of fly ash, crystal phase analysis was conducted by using an X-ray diffraction analyzer, as shown in Fig. 2. Although the fly ash was presumed to be an amorphous substance showing a hollow state in the range of $15 \sim 35^{\circ}$, some quartz $\left(\mathrm{SiO}_{2}\right)$ and mullite $\left(3 \mathrm{Al}_{2} \mathrm{O}_{3} \cdot 2 \mathrm{SiO}_{2}\right)$ were also observed.

Observation results for microstructure of fly ash by using a scanning electron microscope are shown in Fig. 3. As shown here in Fig. 3, the fly ash was observed as a substance of spherical shape, due to which workability is known to be improved by manifesting ball bearing effects when mortar or concrete is mixed.

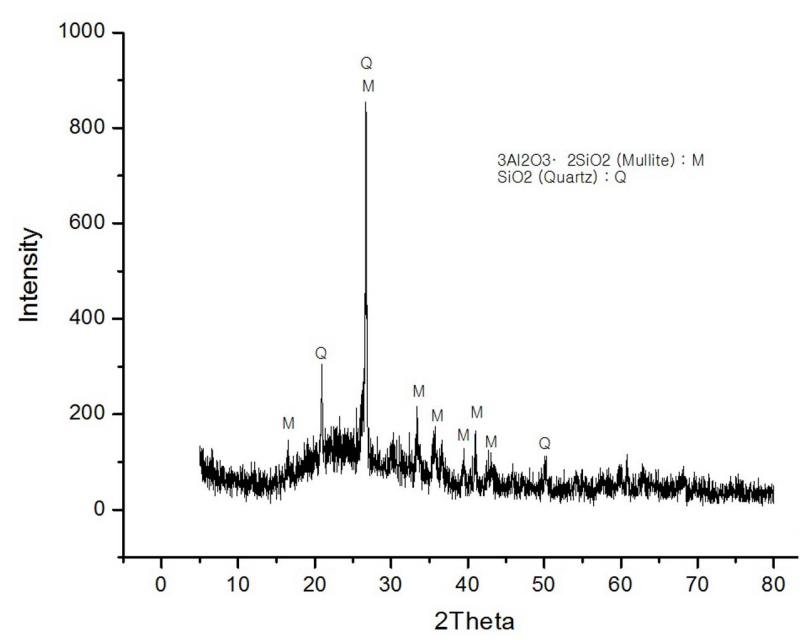

Fig. 2. XRD pattern of fly ash.

Table 1. Chemical Composition of Fly-ash

\begin{tabular}{ccccccccccc}
\hline Comp. & $\mathrm{SiO}_{2}$ & $\mathrm{Al}_{2} \mathrm{O}_{3}$ & $\mathrm{Fe}_{2} \mathrm{O}_{3}$ & $\mathrm{CaO}$ & $\mathrm{MgO}$ & $\mathrm{Na}_{2} \mathrm{O}$ & $\mathrm{K}_{2} \mathrm{O}$ & $\mathrm{SO}_{3}$ & $\mathrm{C}^{-} \mathrm{Cl}^{-}(\mathrm{mg} / \mathrm{kg})$ \\
\hline Content (\%) & 49.9 & 19.2 & 10.1 & 8.21 & 2.84 & 1.01 & 0.72 & 0.71 & 2.64 & 6.22 \\
\hline
\end{tabular}




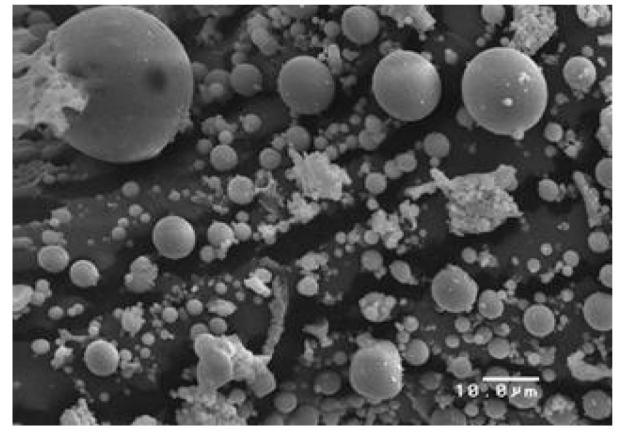

Fig. 3. Microstructure of fly ash.

Table 2. Grinding Medium Characteristic with Various Mill Types

\begin{tabular}{|c|c|c|c|}
\hline & \multirow{2}{*}{$\begin{array}{c}\text { Inner volume }\left(\mathrm{cm}^{3}\right) \\
(\mathrm{D} \times \mathrm{H}, \mathrm{cm})\end{array}$} & \multicolumn{2}{|c|}{ Medium } \\
\hline & & Total weight & Partial weight \\
\hline $\begin{array}{l}\text { Planetary } \\
\text { mill }\end{array}$ & $452(8 \times 9)$ & $500 \mathrm{~g}$ & $\begin{array}{l}\text { Ø } 3 \mathrm{~mm}: 300 \mathrm{~g} \\
\varnothing 10 \mathrm{~mm}: 200 \mathrm{~g}\end{array}$ \\
\hline $\begin{array}{l}\text { Vibratory } \\
\text { mill }\end{array}$ & $7,693(20 \times 24.5)$ & $15 \mathrm{~kg}$ & $\begin{array}{l}\varnothing 26 \mathrm{~mm}: 2 \mathrm{~kg} \\
\varnothing 11 \mathrm{~mm}: 8 \mathrm{~kg} \\
\varnothing 6 \mathrm{~mm}: 5 \mathrm{~kg}\end{array}$ \\
\hline
\end{tabular}

3.1.2. Analysis of characteristics of fly ash as functions of mill types and milling times

Milling characteristics of fly ash as functions of mill types and milling times are analyzed and evaluated. In the present study, the mill types were fixed to be the planetary mill and the vibratory mill. The planetary mill produces centrifugal effects of more than a few ten times by revolving the rotating cylinder. Milling rates are known to be accelerated by such effects. ${ }^{8}$ The vibratory mill belongs to a ball mill in a broad sense, and executes milling by vibrating a cylinder loaded with grinding medium. The charging ratio of balls loaded in the cylinder is known to have a large difference of being higher by about $80 \%$ compared with about $40 \sim 50 \%$ for a ball mill. Also, it has an advantage of having high milling rates since it can produce acceleration by more than a few times in comparison with gravitational acceleration. ${ }^{9)}$ The size of balls loaded inside the mill is also known to affect pulverizability, and the residual amounts show a tendency of being reduced as the size of balls is reduced. Namely, although there is a tendency toward milling into smaller particles when the size of balls is small, it has a disadvantage of milling times being increased. ${ }^{11)}$ In the present study, fly ash was milled by using a planetary mill or a vibratory mill with respective characteristics as shown in Table 2. Ball arrangements in Table 2 represent the results of selection based on the conditions for milling in the shortest time. To analyze milling characteristics of fly ash as functions of mill types and milling times, mean particle diameters and particle size distribution were measured by using a particle size analyzer, with the results shown in Table 3 and Fig. 4. As indicated in Table 3, the tendency in particle size reduction with milling time is gradually weak-

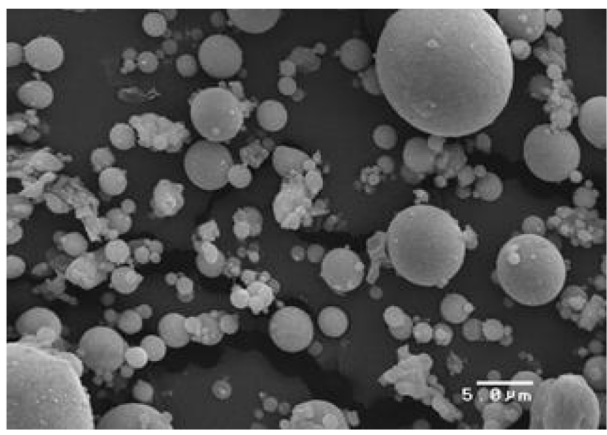

Table 3. Mean Size of Fly Ash

1) Vibratory mill

\begin{tabular}{lccccccc}
\hline Milling time $(\mathrm{min})$ & 0 & 20 & 40 & 60 & 80 & 100 & 120 \\
\hline Mean particle size $(\mu \mathrm{m})$ & 18 & 11.2 & 8.3 & 5.9 & 4.1 & 2.4 & 2.9 \\
\hline 2) Planetary mill & & & & & & \\
\hline Milling time $(\mathrm{min})$ & 0 & 2 & 5 & 10 & 20 \\
\hline Mean particle size $(\mu \mathrm{m})$ & 18 & 10.7 & 5.4 & 0.95 & 0.99 \\
\hline
\end{tabular}

ened, although mean particle diameters were reduced with an increase in milling times. This means that milling becomes more difficult, as the particle diameter becomes smaller, in agreement with the general grinding mechanism.

Figure 5 shows observation of microstructures of fly ash milled for $1 \mathrm{~h}$ using a vibratory mill. Spherical fly ash was changed to fine particles with the spherical shape being broken, and considerable reduction in spherical fly ash could also be observed.

Figure 6 shows XRD patterns of fly ash as a function of mill type and time. The main peak of quartz as the representative crystalline matter present in fly ash exists near $27^{\circ}$, whose peak intensity was detected to be the highest under unground condition. While the peak intensity of the unground fly ash was $854 \mathrm{CPS}$ (count/sec), cases of being lower than the unground case by the maximum of $188 \mathrm{CPS}$ were also observed under the milling conditions in a planetary mill as well as a vibratory mill. It could be inferred that crystallinity became poor and amorphous contents were increased as a result of milling. However, while a change in peak intensities as a function of milling time did not exhibit a clear tendency, some samples also showed rather an increase in peak intensities as the milling time was increased (733 CPS $\rightarrow 762$ CPS, 666 CPS $\rightarrow 762$ CPS).

Vladimir Ronin et al. published activation caused by particle defects upon milling by a vibratory mill, ascribing crack and dislocation as representative particle defects. ${ }^{9-10}$ ) Various particle defects were also subjected to observation by using a transmission electron microscope in the present study, which is shown in Fig. 7. As shown in Fig. 7, defects presumed to be dislocation and crack could also be observed in the present study upon milling in a vibratory mill. Such 


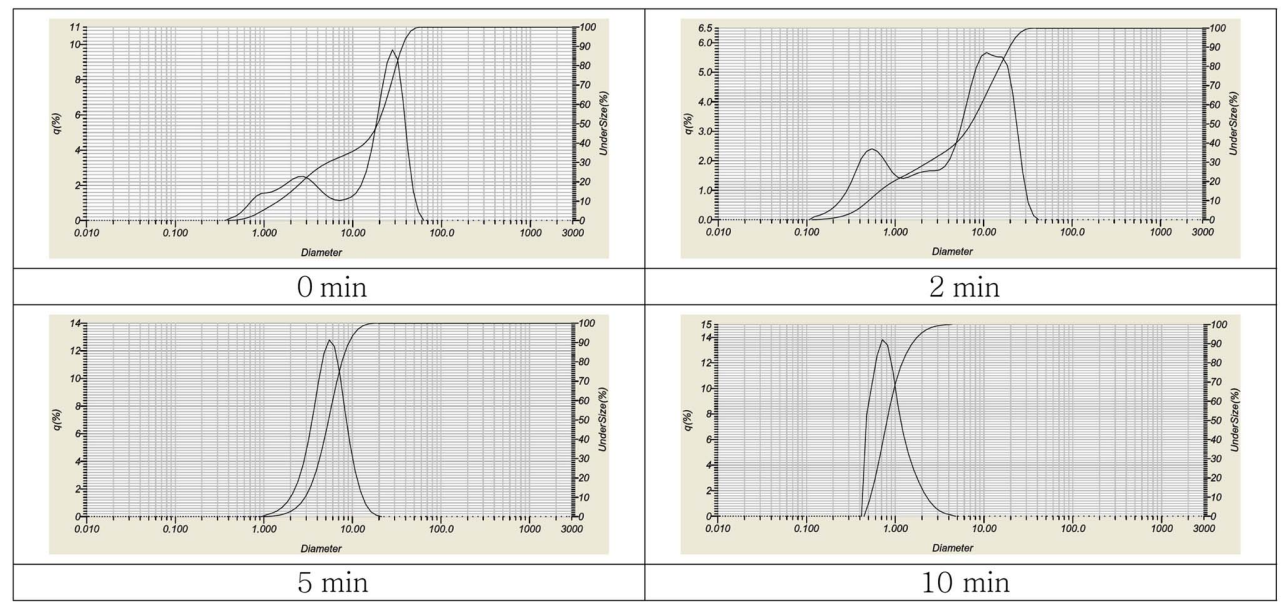

(a) Planetary mill

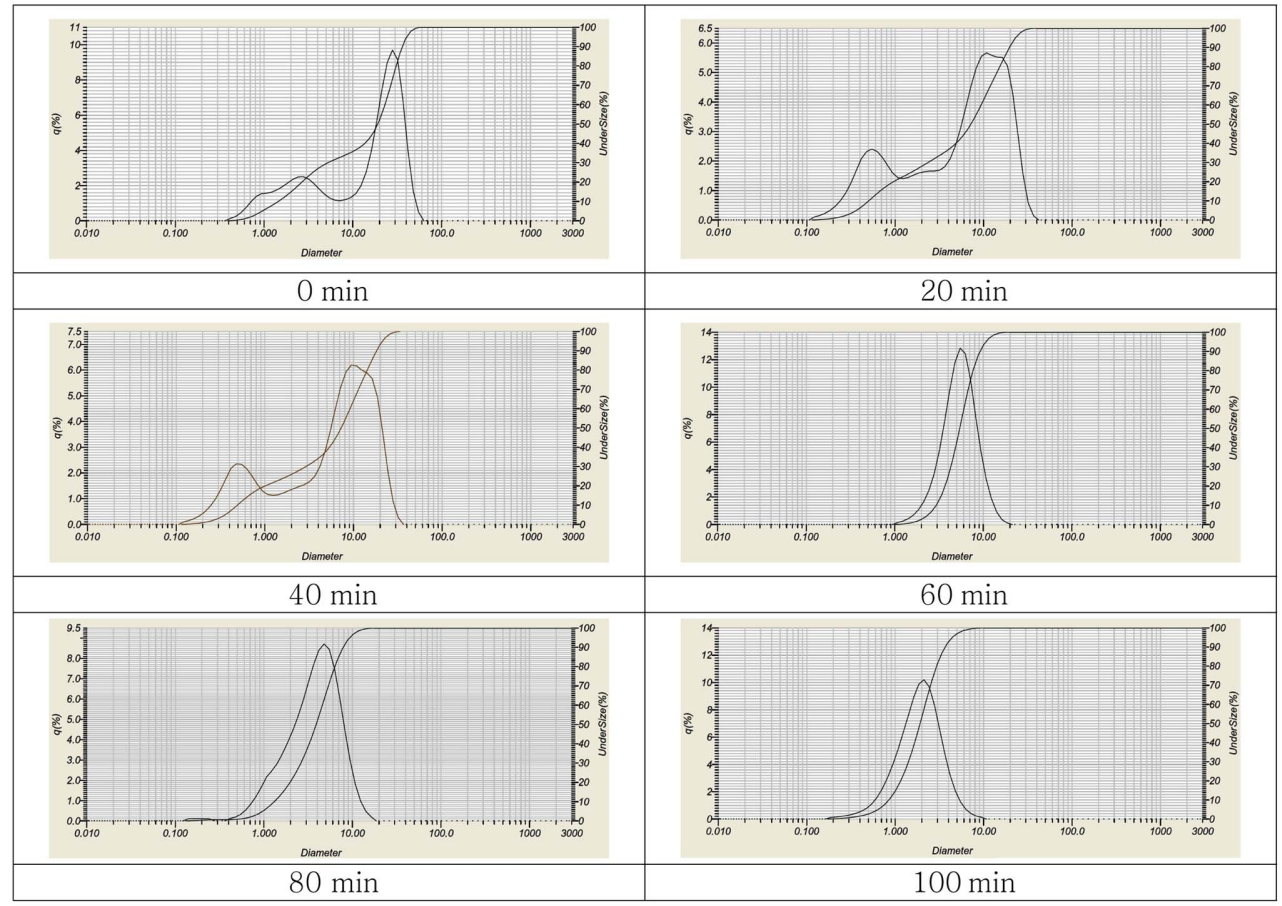

(b) Vibratory mill

Fig. 4. Particle size distribution of fly ash for various milling times.

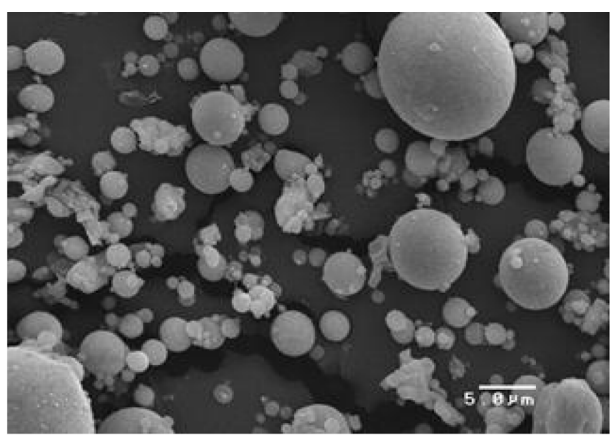

(a) $0 \mathrm{~min}$

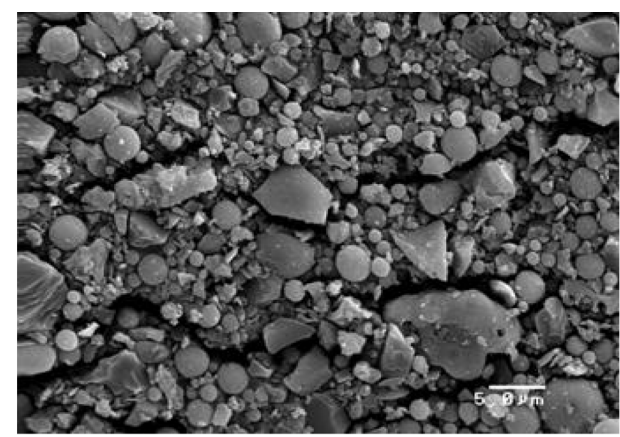

(b) $1 \mathrm{~h}$

Fig. 5. Microstructures of fly ash milled by using a vibratory mill. 


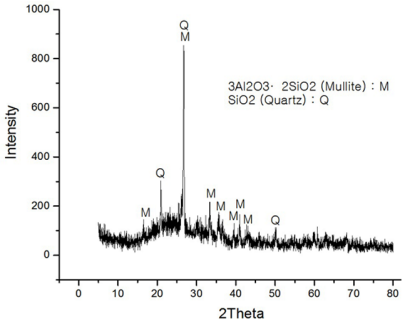

(a) $0 \mathrm{~min} / 854 \mathrm{CPS}$

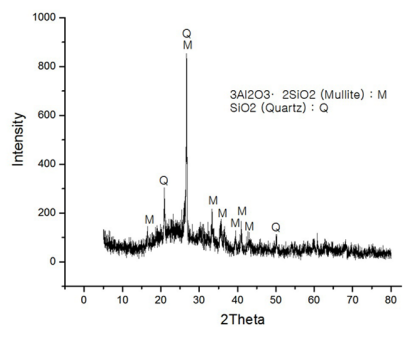

(a) 0 min / 854CPS

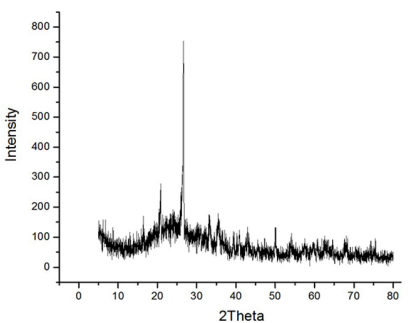

(b) $2 \mathrm{~min} / 733 \mathrm{CPS}$

(a) Planetary mill / Peak Intensity

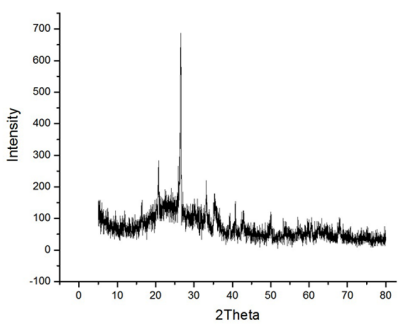

(b) $40 \mathrm{~min} / 666 \mathrm{CPS}$

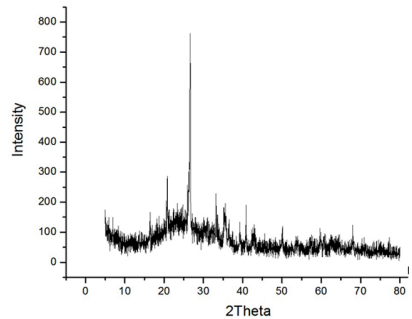

(c) $20 \mathrm{~min} / 762 \mathrm{CPS}$

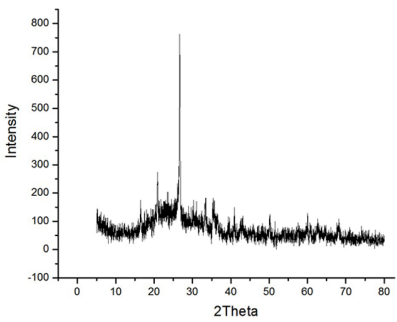

(c) $120 \mathrm{~min} / 762 \mathrm{CPS}$

(b) Vibratory mill / Peak Intensity

Fig. 6. XRD patterns with different grinding conditions.

defects were considered to be capable of raising particle energy, where the raised particle energy could promote pozzolanic reaction in hydration process. ${ }^{9)}$ In fly ash milled in a planetary mill, however, the above defects could not be readily observed.

\subsection{Preparation and evaluation of cement mortar}

To evaluate strength characteristics of mortar mixed with fly ash as a function of mill types and times, physical experiments of cement mortar were conducted. For the physical experiments of cement mortar, mortar was prepared by substitution for $10 \%$ of the cement amount after milling the fly ash in a vibratory mill and a planetary mill. Specimens of $40 \times 40 \times 160 \mathrm{~mm}$ were produced after measurement of the mortar flow. Thus-produced specimens were cured in a constant-temperature water tank at $21^{\circ} \mathrm{C}$, followed by measurement of compressive strengths at the curing ages of 3 days, 7 days and 28 days. As indicated in Fig. 8, the maxi-

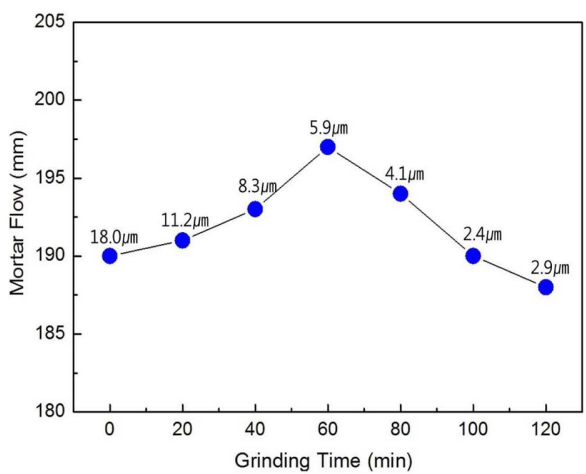

(a) Vibratory mill
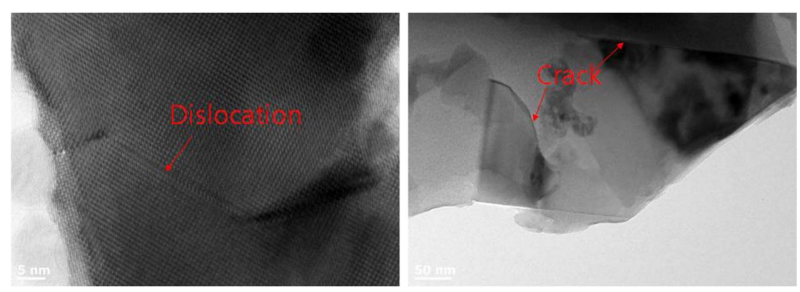

Fig. 7. Defects in grains of milled fly ash.

mum mortar flow value was observed $197 \mathrm{~mm}$ for $60 \mathrm{~min}$ of milling time in a vibratory mill, and $198 \mathrm{~mm}$ for $20 \mathrm{~min}$ milling in a planetary mill. For the planetary milling, the mortar flow showed a tendency of increasing with increase with milling time. For the planetary milling, the mortar flow showed a tendency of increasing with increase with milling times up to $20 \mathrm{~min}$. For the vibratory milling, the flow values decreased when the milling time was increased

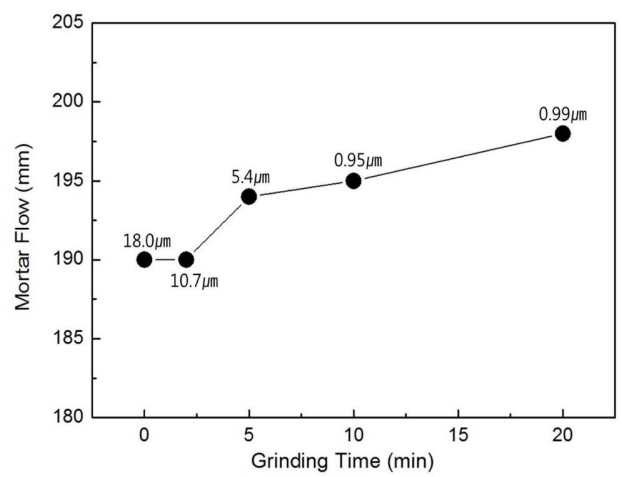

(b) Planetary mill

Fig. 8. Mortar flow as a function of milling times. 


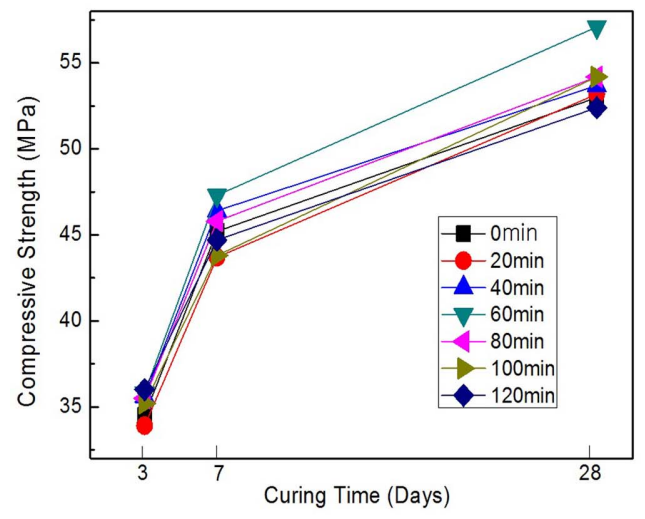

(a) Vibratory mill

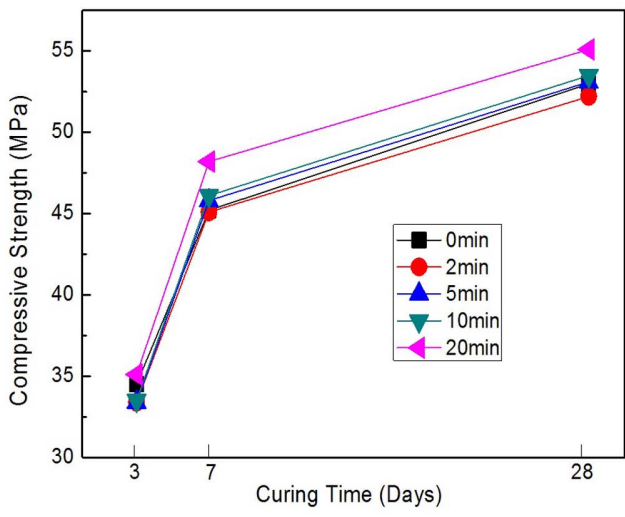

(b) Planetary mill

Fig. 9. Compressive strength for mortar containing $10 \%$ of fly ash.

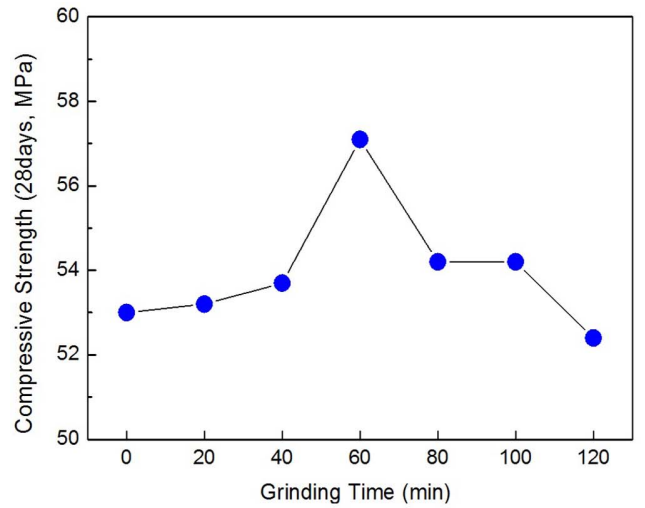

(a) Vibratory mill

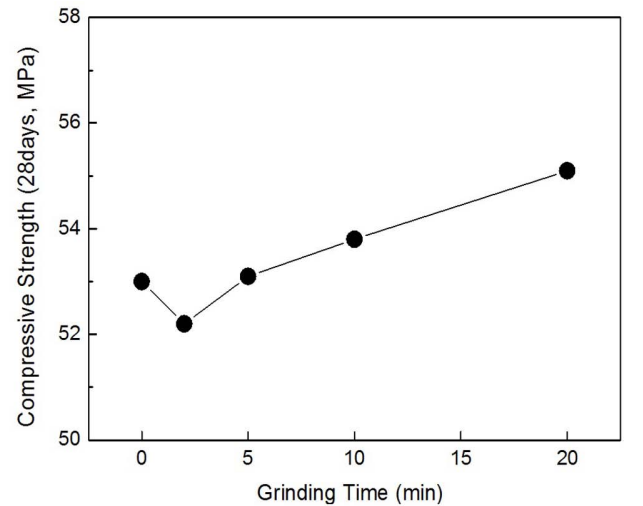

(b) Planetary mill

Fig. 10. Compressive strength of mortar at 28 days as a function of milling time.

to more than $60 \mathrm{~min}$.

Figure 9 shows the measured results of compressive strength for mortar for different milling conditions and curing ages. Whereas the compressive strengths at 3 days, 7 days and 28 days were increased as the milling time was increased to $60 \mathrm{~min}$ upon milling in a vibratory mill, the compressive strength values rather showed the results of being reduced under the conditions beyond $60 \mathrm{~min}$. The maximum compressive strengths under the milling condition of $60 \mathrm{~min}$ were $35.8 \mathrm{MPa}$ at 3 days, $47.3 \mathrm{MPa}$ at 7 days and $57.1 \mathrm{MPa}$ at 28 days. The value for 28 day curing is higher by $4.1 \mathrm{MPa}$ than that of unground fly-ash mortar and by 3.0 MPa than that of OPC. Upon milling in a planetary mill, the maximum value of compressive strength $55.1 \mathrm{MPa}$ was found for 28 days curing of the mortar milled for $20 \mathrm{~min}$. This value is higher by $2.1 \mathrm{MPa}$ when compared with that of unground fly ash, and by $1.0 \mathrm{MPa}$ in comparison with OPC. The maximum compressive strength obtained by planetary milling for $20 \mathrm{~min}$ is somewhat lower than that of vibratory milling for $60 \mathrm{~min}$. Fig. 10 represents more clearly the variation of the compressive strength of the mortar cured for 28 days as a function of milling times. Although the compressive strength values were increased up to $60 \mathrm{~min}$ of milling times in a vibratory mill, a gradual reduction was observed afterwards. For the milling in a planetary mill, compressive strength was increased with increase in milling time.

The above results compare compressive strength values as a function of mill types and milling times, without reflection of the particle size characteristics of milled raw materials. The milling time dependence of compressive strength in Fig. 10 is shown similar to that of the mortar flow in Fig. 8. Therefore, compressive strengths and flow values for the raw materials having the same or similar mean particle diameters should be compared and analyzed. In the present study, particle sizes of the ground raw materials were analyzed, as indicated in Fig. 8. As shown in Table 4, the milling conditions for having similar mean particle diameters were $20 \mathrm{~min}-11.2 \mu \mathrm{m}, 60 \mathrm{~min}-5.9 \mu \mathrm{m}$ for a vibratory mill, and $2 \mathrm{~min}-10.7 \mu \mathrm{m}, 5 \mathrm{~min}-5.4 \mu \mathrm{m}$ for a planetary mill. Namely, similar mean particle diameters around $11 \mu \mathrm{m}$ were exhibited for the conditions of $20 \mathrm{~min}$ in a vibratory mill-2 min in a planetary mill, and those around $5.5 \mu \mathrm{m}$ for the conditions of $60 \mathrm{~min}$ in a vibratory mill- $5 \mathrm{~min}$ in a planetary mill. Compressive strength graph under these conditions is shown in Fig. 11. Although no large difference was observed in compressive strength values as a function of 
Table 4. Comparison of Mean Particle Diameters from Different Milling Conditions

\begin{tabular}{lll}
\hline & $\fallingdotseq 11 \mu \mathrm{m}$ & $\fallingdotseq 5.5 \mu \mathrm{m}$ \\
\hline Vibratory mill & $11.2 \mu \mathrm{m}$ & $5.9 \mu \mathrm{m}$ \\
Planetary mill & $10.7 \mu \mathrm{m}$ & $5.4 \mu \mathrm{m}$ \\
\hline
\end{tabular}

mill type for the mean particle diameter of $11 \mu \mathrm{m}$, higher compressive strength values were manifested upon milling in a vibratory mill in the case of $5.5 \mu \mathrm{m}$. The compressive strengths for the mean particle diameter of $5.5 \mu \mathrm{m}$ were $57.1 \mathrm{MPa}$ in a vibratory mill and $53.1 \mathrm{MPa}$ in a planetary mill, with the difference of $4 \mathrm{MPa}$.

\subsection{Analysis of hydration characteristics}

Cement paste specimens were prepared by controlling the content of mixed water to $40 \%$ in comparison with the content of powder (OPC + fly ash). Crystalline phases were analyzed by XRD and microstructures were observed after the prepared specimens were cured in a constant-temperature water tank at $21^{\circ} \mathrm{C}$.

Fly ash is a representative pozzolan material, and is a substance which causes hydration reaction upon use by mixing with cement as shown by the following expression.

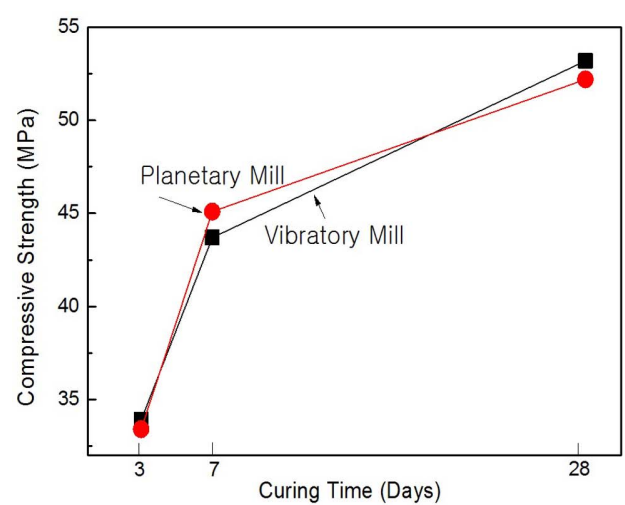

(a) $\fallingdotseq 11 \mu \mathrm{m}$

$$
\begin{aligned}
& \mathrm{Ca}(\mathrm{OH})_{2}+\left[\mathrm{SiO}_{2}, \mathrm{Al}_{2} \mathrm{O}_{3}\right] \rightarrow 3 \mathrm{CaO} \cdot 2 \mathrm{SiO}_{2} \cdot 3 \mathrm{H}_{2} \mathrm{O} \\
& 3 \mathrm{CaO} \cdot \mathrm{Ai}_{2} \mathrm{O}_{3} \cdot 3 \mathrm{H}_{2} \mathrm{O}
\end{aligned}
$$

However, pozzolanic reaction of fly ash is known to take place not at an early stage under general curing conditions but in hydration reaction for a long term. Thus, various measures to promote pozzolanic reaction are being studied, among which the milling technique has been utilized in the present study.

According to the analysis results of XRD patterns in Figs. 12 and $13, \mathrm{Ca}(\mathrm{OH})_{2}$ peak $\left(18.2^{\circ}\right)$ and ettringite peak $\left(9^{\circ}\right)$ could be observed in all XRD patterns. The above peaks correspond to typical hydrates observed in OPC hydrate, and hence the cements prepared in the present study could be presumed to exhibit hydration characteristics similar to those of OPC. Although the XRD pattern from 3 curing days had no large difference between 0 and 60 min milling in the peak intensity of $\mathrm{Ca}(\mathrm{OH})_{2}$, lower peaks could be confirmed for 7 curing days for the $60 \mathrm{~min}$ milling compared to no milling (0 min). Presumably, a faster pozzolanic reaction was induced by milling or grinding. However, such results need further supplementation and substantiation through additional experiments in the future.

Fig. 14 represents observation of the microstructures for the hydrate cured for 7 days using fly ash. It could be con-

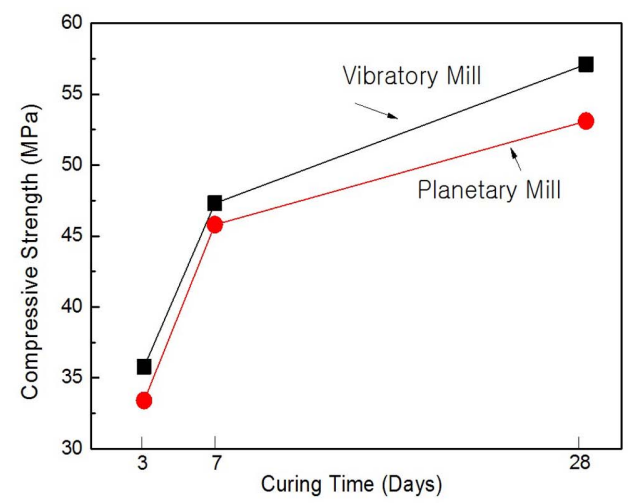

(b) $\fallingdotseq 5.5 \mu \mathrm{m}$

Fig. 11. Compressive strength as a function of mean particle diameter.

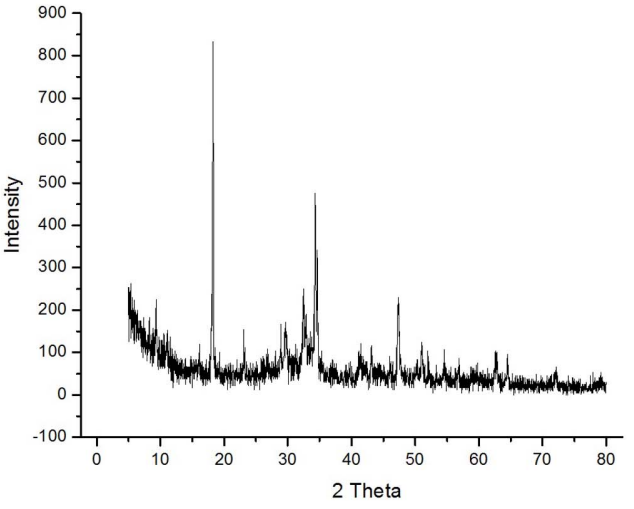

(a) 0 min

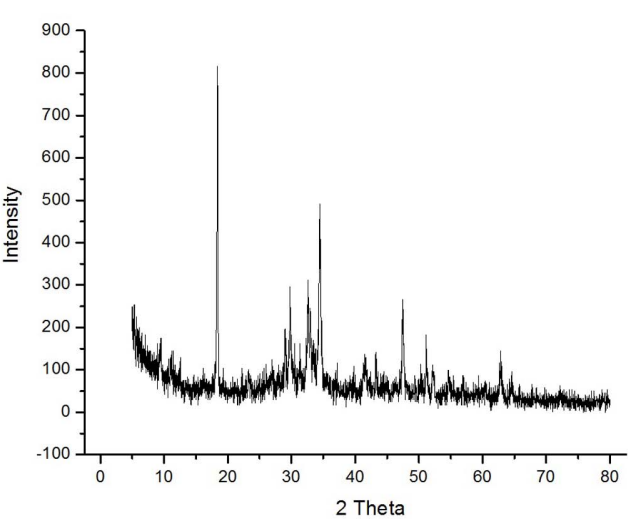

(b) 60 min (vibratory mill)

Fig. 12. XRD patterns of cement hydrates cured for 3 days as a function of milling times. 


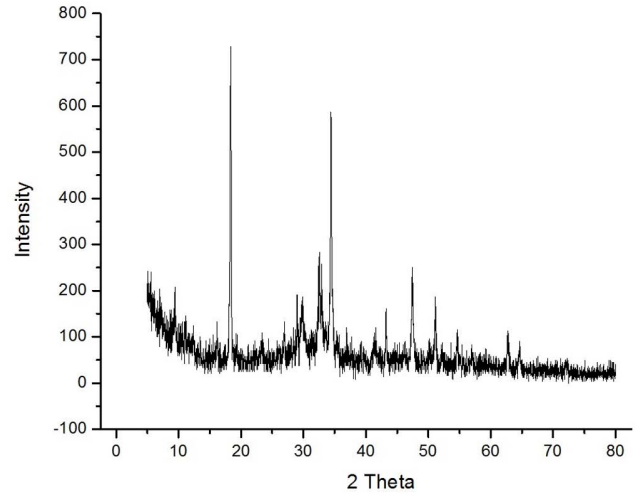

(a) 0 min

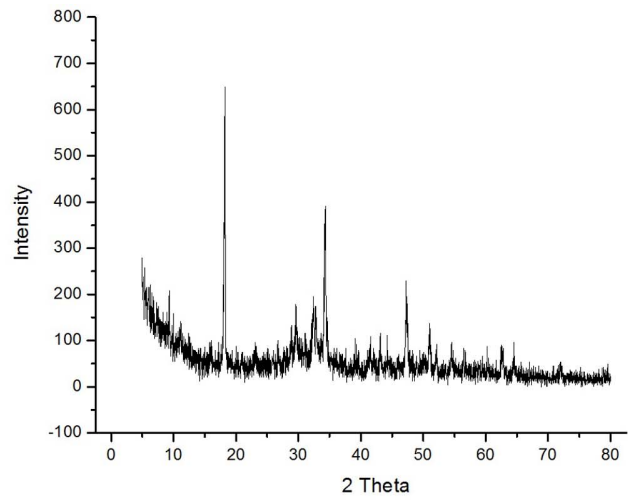

(b) 60 min (vibratory mill)

Fig. 13. XRD of cement hydrates cured for 7 days as a function of milling times.

firmed that the fly ash present in the hydrate mixed with unground fly ash in Fig. 14 (a) showed almost no indication of hydration reaction. However, the hydrate mixed with ground fly ash shown in Fig. 14 (b) hydration reaction occurred in some parts so that fly ash interfaces could not be clearly distinguished. That is, cement hydrate and ground fly ash particles took part in pozzolanic reaction to generate a new hydrated substance at fly ash interfaces. Such characteristics of hydration reaction were considered to be an important aspect which contributed to the enhancement of compressive strength for mortar at an early stage.

\section{Conclusions}

In the present study, development of a manufacturing method of active fly ash from purified fly ash has been attempted, for which mill types and milling times, were controlled. In addition, physical characteristics of mortar mixed with ground fly ash were also analyzed, with the results being as follows.

1. Although quartz peak intensity for the ground fly ash was reduced in comparison with that under the unground
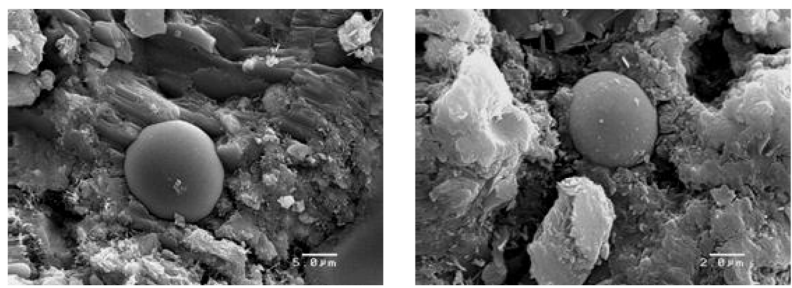

(a) Unground fly ash
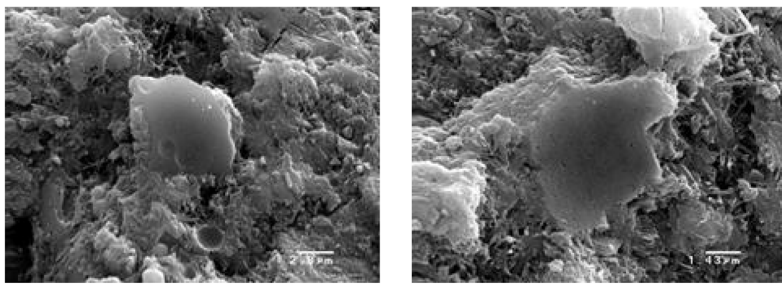

(b) Ground fly ash

Fig. 14. Microstructure of cement hydrates with fly ash. condition, no tendency resulting from an increase in milling time was observed. Also, multitudes of particle defects presumed to be dislocation and crack were observed under the milling condition in a vibratory mill.

2. Flow of the mortar mixed with fly ash showed a tendency of increasing with increase in milling times. However, under milling for more than $60 \mathrm{~min}$ in a vibratory mill, the flow value decreased. The compressive strengths were increased with an increase in milling time in a planetary mill up to $20 \mathrm{~min}$ milling time. The maximum value at $20 \mathrm{~min}$ by planetary milling is somewhat lower than that of $60 \mathrm{~min}$ by vibratory milling.

3. When the mean particle diameter of ground fly ash about $5 \mu \mathrm{m}$ is compared, more excellent compressive strength characteristics were observed for the milling in a vibratory mill rather than in a planetary mill. This was attributed to the fact that cracks, dislocations, etc. existing inside fly ash particles had an effect on hydration reaction (pozzolanic reaction) by milling in a vibratory mill.

4. For the increased utilization of the fly ash, a vibratory mill rather than a planetary mill should be used, and an optimum milling time should be found, since the prolonged milling deteriorated the physical properties. Optimum milling condition promotes the pozzolanic reaction in cement hydration process due to the defects produced inside the fly ash particles.

\section{Acknowledgments}

The present study has been performed under the auspices of Regional specialization project for land traffic technology from Ministry of Land, Infrastructure \& Transport (Project No. : 15RDRP-B066470-03).

\section{REFERENCES}

1. B. P. Kumar and R. Sharma, "Effect of Fly Ash on Engineering Properties of Expansive Soils," J. Geotech. Geoenviron. Eng., 130 [7] 764-67 (2004).

2. H. S. Kim, The Development and Application of Environ- 
ment-Friendly Concrete Using Coal Ash(in Korean), pp. 104, in Master Thesis, Seoul National University of Science and Technology, Seoul, 2008.

3. O. Sengul, and M. A. Tasdemir., "Compressive Strength and Rapid Chloride Permeability of Concretes with Ground Fly Ash and Slag," J. Mater. Civ. Eng., 21 [9] 494-501 (2009).

4. C. C. Wiles, "Municipal Solid Waste Combustion Ash : State of the Knowledge," J. Hazard. Mater., 47 [1] 325-44 (1996).

5. S. I. Kim, J. K. Lee, and C. H. Jeon, "A Study on the Combustion Characteristics of R-UBC in a Drop Tube Furnace"; pp. 93-4 in Proceedings of the Korean Society of Combustion - 48th KOSCO Symposium, Seoul, 2014.

6. H. Justnesa, L. Elfgren and V. Ronin, "Mechanism for Performance of Energetically Modified Cement Versus Corresponding Blended Cement," Cem. Concr. Res., 35 [1] 315-23 (2005).
7. N. Bouzoubal, M. H. Zhang, A. Bilodeau, and V. M. Malhotra, "The Effect of Grinding on the Physical Properties of Fly ash and a Portland Cement Clinker," Cem. Concr. Res., 27 [12] 1861-74 (1997).

8. M. N. Haque1 and O. Kayali, "Propertiese of High-Strength Concrete Using a Fine Fly Ash," Cem. Concr. Res., 28 [10] 1445-52 (1998).

9. H. Justnes, L. Elfgren, and V. Ronin, "Mechanism for Performance of Energetically Modified Cement versus corresponding Blended Cement,“ Cem. Concr. Res., 35 [1] 315-23 (2005).

10. H. Justnes, P. A. Dahl, V. Ronin, J.-E. Jonasson, and L. Elfgren, "Microstructure and Performance of Energetically Modified Cement (EMC) with High Filler Content," Cem. Concr. Compos., 29 [7] 533-541 (2007).

11. Gabor Mucsi, "Grindability of Quqrtz in Stirred Media Mill,” Part. Sci. Technol., 31 399-406 (2013). 